\title{
An analysis of activity timing and mode choice behavior for fixed time workers
}

\author{
Melawaty Agustien ${ }^{1, *}$, Ade Sjafruddin ${ }^{1}$, Harun Al Rasyid S. Lubis ${ }^{1}$, and Sony S.Wibowo ${ }^{1}$ \\ ${ }^{1}$ Civil Engineering Department, Faculty of Civil and Environmental Engineering, Bandung Institute of Technology, 40132 Bandung, \\ Indonesia
}

\begin{abstract}
Generally, the activity based travel demand modeling was resulted from various professions of individuals such as students, workers and non-workers. The model cannot properly represent travel behavior because their characteristics of activities timing and time allocation in a day significantly different. The purpose of this paper is to analyze travel behavior of out of home non-work activities of working groups who have fixed time working hours within a day in location study Palembang City, Indonesia. The effort to explains the travel behavior is conducted through developing activity timing and mode choice model for out of home non work activities. The activity timing and mode choice model are developed as multinomial logit model by adding the utility function of time allocation for non-work activities. There are 9 alternatives in the model in which the alternatives are the combination of 3 activity time schedule and 3 alternative modes. The result of the model significantly reveals that the characteristic of working individuals in deciding certain modes are not only caused by the mode attributes, such as travel time and cost, but also by the type and time allocation for non-working activities related to that travel.
\end{abstract}

\section{Introduction}

One of the advantages of the activity based travel demand model compared to the trip based and tour based approach is the ability of these models explicitly considering the time dimension in its analysis Pas and Harvey (1997), Shiftan Joram et.al (2003). Two dimensions of time are generally considered in the model is the activity timing that shows when the activity performed and time allocation shows how long the activity performed. Bhat (2009), Yagi S. and Mohammadian, A. (2006) argue that individual travel patterns is a result of the decision of the use of time to travel and activities. Research conducted by Fujiwara et.al (2010) indicates that the value of the utility of the activity based on the time allocation to do these activities can affect the pattern of travel in one day. Identification of changes in travel patterns made by individuals as a result of changes in the value of the utility of the activity can be used for prediction of the number of travel especially during rush hour morning, noon and evening Yamamoto and Kittamura (2009). Based on the research by Meloni, et al (2010), some one has to split time for activities and trips due to the time limitations in a day. In addition, modeling and analysis of the allocation of time is an important element in the development of transportation planning methodology.

This study contributes to the literature on activity and travel analysis by developing a comprehensive out-of- home non-work activity based travel demand model for fixed time workers. The periods of the day are defined based on the representation framework used by Bhat and Singh (2000) to describe the daily activitytravel patterns of workers. According to this framework and based on the temporal fixities of the work schedule, a worker's day is divided into the following three broad periods: (1) Home-to-work commute period, (2) Workbased period (3) Post home-arrival period and three modes of transport ; private car, private motorcycle and public transport. A multinomial logit model represents the alternative combination in conducting travel with respect to the aforementioned periods and modes of transport. The alternative attributes are divided into four attributes associated with the characteristics of the activities, characteristics of the travel, as well as individual and household social economic. Different from ordinary transport mode choice model, modification of multinomial logit model is conducted by substituting utility of time allocation component besides utility of travel. The utility of time allocation model is based on the utilitarian resource allocation theory, which states that an individual allocates available time to each activity such that the total utility derived from all activities will be maximized.

The next section will explain methodology and estimation procedure of the model. Data description is presented in the third section. The collected data is the result of interviews and questionnaires of the activities and travel performed in one day. The results of the

\footnotetext{
* Corresponding author: melawaty15@gmail.com
} 
empirical analysis will be described in the fourth section, followed by a conclusion in the last section.

\section{Modelling methodology and estimation procedure}

The modification of utility function was used in the choice model of activity timing and transportation mode for out of home non work activities. The total utility of choosing alternatives is modeled to be the sum of the utility associated with the characteristic of travel and out of home non work activities. Individual chooses the activity timing and transport mode to maximize the utility associated with the travel and activities before and after the travel.

A unique feature of the model system of this study is that time allocation for non-work activity is analyzed in conjunction with the travel time and the time schedule of work activities before and after the non work activity. It is expected, that the separation of the travel time from the total time allotted for out of home non work activities can be used as a tool capable of capturing the direct consequences of modifications to an individual's time avaibility. For example, an improvement in the level of service of transport system will reduce travel time and the time saved can be spent in non work activities that generate trips.

The model system of non work activity and travel used to describe activity timing and mode choice is developed as a multinomial logit model based on utilitarian resource time allocation theory representing the combination alternatives between conducting non-work activities before work, after work and after returning home and three modes of transport, namely private car, private motorcycle and public transport.

The assumptions used in the model structure were developed based on the equations developed by Yamamoto and Kittamura (2009). In this study, the activity timing and mode choice are based on the utility value of the travel and out of home non work activity choices associated with the travel. The activity timing and mode utility $(i)$ is:

$$
\begin{gathered}
U_{i}=U T_{i}+U A_{i} \\
U T_{i}=\gamma \quad X_{i}+\varepsilon_{i} \\
U A_{\mathrm{i}}=\sum_{j} U A_{j i} \\
U A_{\mathrm{ji}}=\quad \alpha_{\mathrm{Aji}} \operatorname{lnt}_{\mathrm{ji}}=\exp \left(\beta \mathrm{X}_{\mathrm{Aji}}+\varepsilon_{\mathrm{Aji}}\right) \operatorname{lnt}_{\mathrm{ji}}
\end{gathered}
$$

where:

$i \quad$ : combination of mode used and activity timing

$U_{i} \quad:$ total utility

$U T_{i} \quad$ : the utility of the trip

$\gamma \quad$ : vector of Coefficient

$X_{i} \quad$ : vector of explanatory variable associated with the travel characteristic

$\varepsilon_{\mathrm{i}} \quad:$ random error term of the utility of the travel

$U A i \quad$ : sum of the utilities of all activities associated with the alternative $i$

$U A j i \quad$ : utility of engaging in the jth non work activity of the day associated with the alternative $i$
$\beta \quad$ : vector of coefficients
XAji : vector of explanatory variables
$\varepsilon A j i \quad$ : random error
tji : time spent on the jth activity associated with the alternative $i$

The value of parameter $\beta$ in equation (4) is estimated by least squares regression assuming $\varepsilon_{A j i}-\varepsilon_{A j ' i}$ is a normal random variate with a mean of 0 and a variance of $\sigma^{2}$ :

$$
\ln \left[\frac{t_{A j i}}{\mathrm{t}_{\mathrm{k}}-\mathrm{t}_{\mathrm{k}-1}-\mathrm{t}_{\text {trip }}}\right]=\beta\left(\mathrm{X}_{\mathrm{Aji}}-\mathrm{X}_{\mathrm{Aji}}\right)+\left(\varepsilon_{A j i}-\varepsilon_{A j^{\prime i}}\right)
$$

where:

$t^{*}{ }_{A j i} \quad$ : the optimum time allocation of all non work

$t_{k} \quad:$ the time when the last activity starts after non work activivity

$t_{k-1} \quad:$ the time when the last activity ends before non work activivity

$\mathrm{t}_{\text {trip }} \quad:$ travel time

The discrete choice of the alternative combination in conducting out of home non-work activity during the three commuting periods and the three modes of transport is formulated as a multinomial logit model assuming the random variables, $\varepsilon_{i}, \mathrm{~s}$, are independently $\&$ identically standard extreme value distributed (IID) with a Gumbel distribution. The parameter vector, $\gamma$, is estimated by the method of maximum likelihood. The probability of choosing an alternative $i, \operatorname{Pr}(i)$, is given as,

$$
\mathrm{P}_{\mathrm{r}}(i)=\frac{\exp \left[\gamma \mathrm{X}_{\mathrm{i}}+\mu \sum_{j=1}^{J} \exp \left(\hat{\beta} X_{A j i}\right) \ln \left(t_{j i}^{*}\right)\right]}{\sum_{i=1}^{12} \exp \left[\gamma \mathrm{X}_{\mathrm{i}}+\mu \sum_{j=1}^{J} \exp \left(\hat{\beta} X_{A j i}\right) \ln \left(t_{j i}^{*}\right)\right]}
$$

where:

$\gamma \quad$ : coefficient vector

$X_{A j i}$ : vector of independent variables for out of home non work activity choice to $j$ when the alternative $i$ is chosen

$\hat{\beta} \quad$ : estimated coefficient vector

$t^{*} j i$ : optimum duration of out of home non work activity to $j$

There are 9 alternatives being considered in the multinomial logit model in which the alternatives are the combination of 3 activity time schedule and 3 alternative modes. The alternatives of activity time schedule are home-work period, work-based period and post home period. The alternative modes are consisted of private cars, private motorcycles, and public transport. Alternative combination of activiti timing and mode choice are explained on table I below. 
Table 1. Alternative combination of Activiti timing and mode choice

\begin{tabular}{|c|l|c|}
\hline No & $\begin{array}{c}\text { Alternative Combination of Activiti } \\
\text { Timing and Mode Choice }\end{array}$ & Variable \\
\hline 1 & Before Work - private car & $\mathrm{T}_{1} \mathrm{~m}_{1}$ \\
\hline 2 & Work Based - private car & $\mathrm{T}_{2} \mathrm{~m}_{1}$ \\
\hline 3 & Post Home - private car & $\mathrm{T}_{3} \mathrm{~m}_{1}$ \\
\hline 4 & Before Work - private motorcycle & $\mathrm{T}_{1} \mathrm{~m}_{2}$ \\
\hline 5 & Work Based - private motorcycle & $\mathrm{T}_{2} \mathrm{~m}_{2}$ \\
\hline 6 & Post Home - private motorcycle & $\mathrm{T}_{3} \mathrm{~m}_{2}$ \\
\hline 7 & Before Work - public transport & $\mathrm{T}_{1} \mathrm{~m}_{3}$ \\
\hline 8 & Work Based - public transport & $\mathrm{T}_{2} \mathrm{~m}_{3}$ \\
\hline 9 & Post Home - public transport & $\mathrm{T}_{3} \mathrm{~m}_{3}$ \\
\hline
\end{tabular}

\section{Data description}

The data set is derived from a comprehensive survey of household demographical information, out of home non work activity and travel caracteristic that was collected in 2014 in Palembang. Palembang is capital city of South Sumatera and one of the cities in Indonesia. The survey was conducted using activity and travel diary quesioner survey method. The sampling location incorporated in this observation is spread across in 16 sub-districts in the city of Palembang. The number of samples collected are as many as 300 peoples.

The demographic data such as gender, age, occupation, household income, the number children in school age, the type and number of vehicle ownership. From the total number of respondents, 300 respondents, there were 129 male (43\%) and 171 female (57\%). The respondents were mostly of a working-age of 26 to 55 years old and not only have fixed time work schedules but also have non-work activities.

There are some variations in out of home non work activities, including social activities such as visiting family or friends, meetings, shopping, doing sports and entertainment. Some respondents have chosen more than one out of home non work activity. These activities were conducted in the morning before working, during their lunch break and after returning home.

Based on the survey results there were 505 out of home non work activities which are observed from 300 respondents. Figure 1 to 3 show that time allocated to perform the out of home non work activities is greater than the allocation of time allotted for travel time either the home-work, work based or post home periodes. The average of trip time during work based periode is 20 minutes. There was a relatively a short time, this was due to the shorter duration at lunch break which is ranging from 1 to 1.5 hours. The average of trip time in the post home periode for entertainment and socialization activities are 30 minutes while the average of trip time for meeting activity is 50 minutes. This phenomenon shows that each observation periods has their own travel and activity time use characteristic. This information is important to analyze the travel characteristic based on activity time allocation before and after the trip and to determine how people try to maximize utility of their time allocation to do some non-work activities and travel in one day.

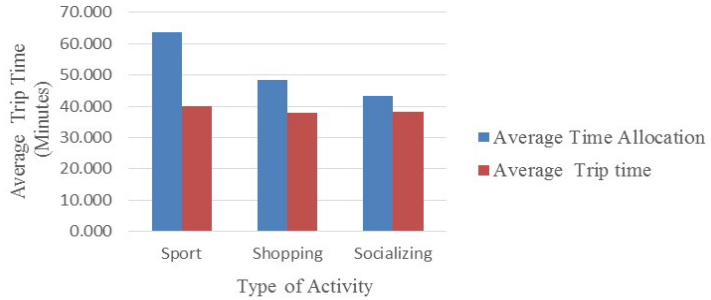

Fig. 1. Average time allocated for non work activity and travel time of before work (home-work) period $\left(\mathrm{T}_{1}\right)$

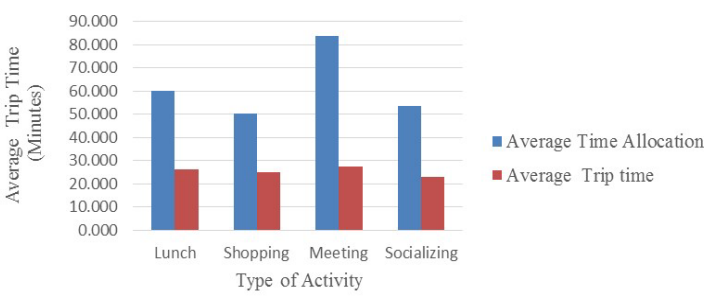

Fig. 2. Average time allocated for non work activity and travel time of work-based periode $\left(\mathrm{T}_{2}\right)$

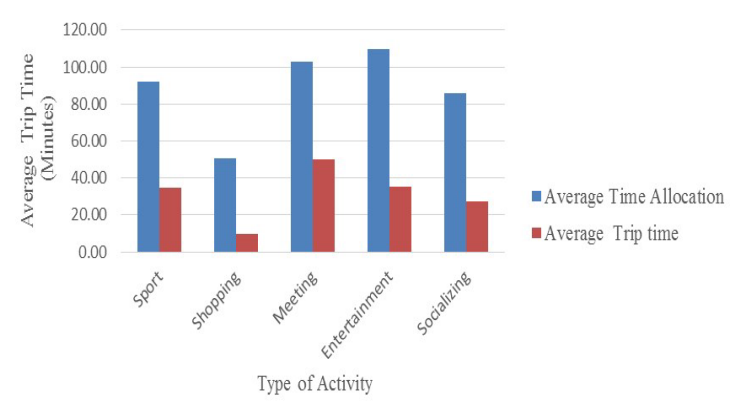

Fig. 3. Average time allocated for non work activity and travel time of post home periode $\left(\mathrm{T}_{3}\right)$

Table 2. Number of activities based on mode choice and non work time allocation

\begin{tabular}{|l|c|c|c|c|}
\hline \multirow{2}{*}{ Mode Choice } & \multicolumn{3}{|c|}{ Out of home non work time } & \multirow{2}{*}{ allocation } \\
\cline { 2 - 4 } & $\begin{array}{c}<\mathbf{1} \\
\text { Hour }\end{array}$ & $\begin{array}{c}\mathbf{1 - 3} \\
\text { Hour }\end{array}$ & $\begin{array}{c}>\mathbf{3} \\
\text { Hour }\end{array}$ & \\
\hline Private car & 46 & 50 & 124 & 220 \\
\hline $\begin{array}{l}\text { Private } \\
\text { motorcycle }\end{array}$ & 32 & 90 & 68 & 190 \\
\hline $\begin{array}{l}\text { Public } \\
\text { transport }\end{array}$ & 28 & 41 & 26 & 95 \\
\hline Total & 106 & 181 & 218 & 505 \\
\hline
\end{tabular}

The relationship between alternative modes and out of home non work time allocation can be seen on table II. Respondents who allocate 1-3 hours for non work activities tend to use a private motorcycle, whereas respondents who allocate more than 3 hours tend to use a private car. This is caused by the type of activity and the number of family members who participated in the trip to perform these activities. The time allocation of more than 3 hours is generally used for entertainment activities that involve more family members so that car is generally used for these activity. 


\section{Estimation parameters of the activity timing and mode choice model}

Model parameters are estimated using the household demographical information and daily out of home non work activity diary and travel caracteristic. In first phase, the data on the time allocation to out of home non workactivities are used to estimate the vector parameters $\beta$ by using ordinary least-squares regression.

The time allocation of 505 non work activities are recapitulated to estimate the values of the vector parameters in equation 4 . The explanatory variables in the model are summarized in Table 3.

Table 3. Explanatory variable used in time allocation model and multinomial logit

\begin{tabular}{|c|l|c|}
\hline $\begin{array}{c}\text { Alternative } \\
\text { Attribute }\end{array}$ & \multicolumn{1}{|c|}{ Explanatory Variable } & $\begin{array}{c}\text { Variabel } \\
\text { Name }\end{array}$ \\
\hline \multirow{4}{*}{$\begin{array}{c}\text { Trip } \\
\text { Attribute }\end{array}$} & Travel time from office & $\mathrm{X}_{1}$ \\
\cline { 2 - 3 } & The travel time from home & $\mathrm{X}_{2}$ \\
\cline { 2 - 3 } & Travel cost from office & $\mathrm{X}_{3}$ \\
\cline { 2 - 3 } & Travel cost from office & $\mathrm{X}_{4}$ \\
\hline \multirow{4}{*}{$\begin{array}{c}\text { Individual } \\
\text { and } \\
\text { Household } \\
\text { Attribute }\end{array}$} & Public Servants & $\mathrm{X}_{5}$ \\
\cline { 2 - 3 } & Private Employment & $\mathrm{X}_{6}$ \\
\cline { 2 - 3 } & Entrepreneurs & $\mathrm{X}_{7}$ \\
\cline { 2 - 3 } & member & $\mathrm{X}_{8}$ \\
\cline { 2 - 3 } & Household income & $\mathrm{X}_{9}$ \\
\cline { 2 - 3 } & Car ownership & $\mathrm{X}_{10}$ \\
\cline { 2 - 3 } & Motorcycle ownership & $\mathrm{X}_{11}$ \\
\hline \multirow{2}{*}{$\begin{array}{c}\text { Activity } \\
\text { Attribute }\end{array}$} & Hobby & $\mathrm{X}_{12}$ \\
\cline { 2 - 3 } & Social & $\mathrm{X}_{13}$ \\
\cline { 2 - 3 } & Entertainment & $\mathrm{X}_{14}$ \\
\hline
\end{tabular}

Not all of the explanatory variables in the model are considered significant. It is due to the low correlation between explanatory and dependent variable in time allocation model. Based on the $\mathrm{t}$ statistic value of explanatory variable obtained from the model, some individuals, households and activity attributes are found to significantly influence time allocation behavior. The explanation of each attributes which influences time allocation from the observed activities is outlined in table 4.

Among the explanatory variables, the number of family members attending school has a negative coefficient estimate and the largest t-statistic. It indicates that the respondents who have more family members attending school tend to have less time availablitity to do non work activities to maximize the utility of the activity time allocation.

Respondents who have a job in the private employment sector also tend to have less time availablitity to do non work activities than respondents who work as government employmees and entrepreneurs. This is due to the fixed work activity schedule for private employment so that the respective respondents have to allocate their time to do work and non work activities effectively.
Table 4. Parameter estimation of regression model of time allocation

\begin{tabular}{|l|c|c|c|}
\hline Explanatory Variable & $\begin{array}{c}\text { Variabel } \\
\text { Name }\end{array}$ & $\begin{array}{c}\text { Coeffic } \\
\text { ient }\end{array}$ & t-Stat \\
\hline Private Employment & $\mathrm{X}_{6}$ & -0.191 & -3.979 \\
\hline $\begin{array}{l}\text { Number of family } \\
\text { member attending school }\end{array}$ & $\mathrm{X}_{8}$ & -0.159 & -6.266 \\
\hline Household income & $\mathrm{X}_{9}$ & 0.199 & 6.033 \\
\hline Car ownership & $\mathrm{X}_{10}$ & 0.156 & 3.507 \\
\hline Motorcycle ownership & $\mathrm{X}_{11}$ & -0.058 & -1.224 \\
\hline Hobby & $\mathrm{X}_{12}$ & 0.003 & 0.068 \\
\hline Social & $\mathrm{X}_{13}$ & 1.812 & 2.698 \\
\hline Entertainment & $\mathrm{X}_{14}$ & 0.325 & 0.789 \\
\hline
\end{tabular}

Household income has a statistically significant positive coefficient estimate, indicating that respondents who have a higher income tend to have more time available to do non work activities. It shows that based on the survey result number of trips is significantly influenced by household income. Families with higher income tend to do more out of home non work activities than respondents who have a lower income.

Car ownership variable also influences time allocation to do out of home non work activities. To maximize the utility of time allocation of the activities, respondents with a greater number of car ownership tend to allocate a greater expenditure of time to do the activities.

Besides individual and household attributes, activity attribut influences the utility of time allocation of nonwork activities. The positive sign of variable social of doing the activity means that there is a longer time to do non work social activities.

Using the estimated parameters as presented in table IV, the optimum durations of the activities are calculated to be used in the estimation of a multinomial logit model. The estimation results are presented in table V(a) and $\mathrm{V}(\mathrm{b})$. The explanation about symbol of variabel can be seen on table I and table III. The likelihood ratio statistics indicate the model is highly significant. It means that the model can be used to predict the combination alternatives of acticity timing and transport modes based on social economic condition of individual and household, activity and travel characteristics.

The base alternative is doing out of home non work activity in the post home period using public transport. T-statistic value of each variables indicates that sosiodemographic, activity and trip characteristic variables are found to influence activity timing and mode choice. The alternative specific constant in the model shows that, relative to the using public transport at post home period, there is a greater likelihood of pursuing the out of home non wok activity in the home-work, work based and after returning home periods using car, motorcycle or public transport mode. All of the alternatives spesific constants are found to be positive and significant. The greatest likelihood occurs in the combination alternative cars-after returning home period. 
Table 5 (a). Parameter estimation of multinomial logit model

\begin{tabular}{|c|c|c|c|c|c|c|c|}
\hline \multirow{2}{*}{$\begin{array}{c}\text { Alter } \\
\text { natif }\end{array}$} & \multicolumn{7}{|c|}{ Estimated parameter } \\
\cline { 2 - 8 } & $\mathbf{C}$ & $\boldsymbol{U A \boldsymbol { i }}$ & $\mathbf{X}_{\mathbf{1}}$ & $\mathbf{X}_{\mathbf{2}}$ & $\mathbf{X}_{\mathbf{3}}$ & $\mathbf{X}_{\mathbf{4}}$ & $\mathbf{X}_{\mathbf{5}}$ \\
\hline $\mathrm{T}_{1} \mathrm{~m}_{1}$ & 242.3 & 387.24 & & -206.7 & -0.07 & -0.05 & 27 \\
\hline $\mathrm{T}_{2} \mathrm{~m}_{1}$ & 533.6 & 26.35 & -114.3 & -72.5 & -0.01 & -0.05 & \\
\hline $\mathrm{T}_{3} \mathrm{~m}_{1}$ & 629.1 & 266.91 & & -5.7 & -0.01 & -0.03 & 41 \\
\hline $\mathrm{T}_{1} \mathrm{~m}_{2}$ & 542.2 & 26.06 & -53.81 & & -0.07 & & \\
\hline $\mathrm{T}_{2} \mathrm{~m}_{2}$ & 208.6 & 362.74 & -207.6 & -152.8 & & -0.02 & 18 \\
\hline $\mathrm{T}_{3} \mathrm{~m}_{2}$ & 520.1 & 149.36 & -86.4 & & -0.01 & & 33 \\
\hline $\mathrm{T}_{1} \mathrm{~m}_{3}$ & 281.6 & 281.63 & & & -0.01 & & \\
\hline $\mathrm{T}_{2} \mathrm{~m}_{3}$ & 273.6 & 273.63 & & & -0.02 & & 32 \\
\hline
\end{tabular}

Table 5 (b). Parameter estimation of multinomial logit model

\begin{tabular}{|c|c|c|c|c|c|c|c|c|}
\hline $\begin{array}{c}\text { Alter } \\
\text { natif }\end{array}$ & $\mathbf{X}_{\mathbf{6}}$ & $\mathbf{X}_{\mathbf{7}}$ & $\mathbf{X}_{\mathbf{8}}$ & $\mathbf{X}_{\mathbf{9}}$ & $\mathbf{X}_{\mathbf{1 0}}$ & $\mathbf{X}_{\mathbf{1 1}}$ & $\mathbf{X}_{\mathbf{1 2}}$ & $\mathbf{X}_{\mathbf{1 3}}$ \\
\hline $\mathrm{T}_{1} \mathrm{~m}_{1}$ & -26 & & -5 & & 33 & 13 & -5 & -7 \\
\hline $\mathrm{T}_{2} \mathrm{~m}_{1}$ & & 41 & & 5 & 47 & 17 & & 4 \\
\hline $\mathrm{T}_{3} \mathrm{~m}_{1}$ & 42 & & & 34 & 43 & 32 & 8 & 5 \\
\hline $\mathrm{T}_{1} \mathrm{~m}_{2}$ & & 79 & & 6 & 43 & & & \\
\hline $\mathrm{T}_{2} \mathrm{~m}_{2}$ & & & -7 & 6 & & 18 & 6 & 7 \\
\hline $\mathrm{T}_{3} \mathrm{~m}_{2}$ & 19 & 47 & 57 & 4 & 62 & 18 & & 4 \\
\hline $\mathrm{T}_{1} \mathrm{~m}_{3}$ & -87 & 27 & & 4 & & & 4 & 8 \\
\hline $\mathrm{T}_{2} \mathrm{~m}_{3}$ & & & -7 & 11 & 53 & & & \\
\hline $\mathrm{T}_{3} \mathrm{~m}_{3}$ & 17 & & & & & & 9 & 7 \\
\hline
\end{tabular}

Respondents in the private employment sector appear to show a greater propensity to pursue out of home non work activities in the after returning home periode with private car as a mode to conduct the activity.This may be due to the tight work schedule and the need to allocate more time to do out of home non work activity. Another significant variable is the value of utility of time allocation which has positive coefficient value for all alternatives. This means the alternative activity timing and mode of transport with the greater activity utility value tends to be preferred. Travel time from home to activity locations has negative coeficient variables, implying that the alternative activity timing and mode choices which facilitate for shorter time to get home tend to be preferred. Similarly for alternatives with a higher the travel costs which have negative coefficients, will change an individual's activity timing and mode choice.

The empirical result shows that the activity attributes which are considered in the model generate significant value. It shows for out of home non work activity destination traveller will consider the utility value of the activity when making decisssion about activity timing and transport modes for conducting the activity.

\section{Conclusions}

The results of the activities and trip data collection which were conducted in Palembang indicate a variation in the out of home non work activity schedule and selecting mode used to perform the activities. Activities at work-based period are dominated by lunch outside the office with public transportation as mode of transport.
The activities conducted at post home period were dominated by entertainment activities using private cars.

The importance of time allocation to conduct activities is greater than trip time either in the morning before working, during the day at lunch break or post home periods. The results of utility time allocation model show that there are several variables involving individual and household social economic condition, as well as those of the activity characteristics, that influence the out of home non work activity time allocation. Some variables such as the number of family attending school and private employment as a type of job have a negative coefficient estimates and largest tstatistic values. It indicates that the respondents who have more family members attending school and private employment jobs tend to have less time available to do non work activities to maximize their utility time allocation for non work activities. The condition is may be due to the responsibility of respondents as a parents who have to take care their children and fix the time of their activity schedule for private employment. These respondents would then have to allocate their time more effectively to do work and non work activities.Similiarky for respondents who have a higher income and have more car ownership tend to allocate a greater expenditure of time for the activity. This indicate that the value of utility derived from out of home non-work activities increase in directly proportion to the level of individual and family income

Significance of multinomial logit model is showed by value of Pseudo $R^{2}$ is 0.36 which is equivalent with 0.65 in regression model. This indicates that the model is good enough to use for prediction. The significance of utility of time allocation variable and a positive value of the variable's coefficient show that the choice of activity timing and transport mode for non work activity are influenced by the utility of the activity. Respondents will choose the alternative with longer activity time allocation even though the cost of the transport mode alternative may be more expensive.

The results of the model show that the decision of choosing the activity timing and transport mode for travel-related non-work activities is not only influenced by attributes such as cost and travel time, but also by the type of activites that will be performed and the socio-economic condition of the travelers. Based on the results, it can be seen that the understanding of individuals' activity based travel behavior is more comprehensive compared to that of trip and tour based travel behavior. This understanding is thus expected to be relied upon in drafting policies that are associated with travel demand management at a particular time and location.

\section{References}

1. Bhat, C.R., and S.K. Singh., Transportation Research Part A 34, p : 1-12, 1 (2000)

2. Bhat, C.R, et.al, Transportation Research Record, 2134, p : 51-62, (2009)

3. Fujiwara, et. al., Journal EASTS, 8, (2010) 
4. Meloni, I., E. Spissu, and M. Bez., Transportation Science 41, pp. 15-28, 1 (2007)

5. Pas, E.I. and Harvey, A.S, Transport Policy, 225235(1997)

6. Yagi, S. and Mohammadian, A., Proceedings of the 11th International Conference for Travel Behaviour
Research Conference (IATBR), Kyoto, Japan, (2006)

7. Yamamoto, T., dan R. Kitamura, Transportation, 26, p : 211-2302, (2009)

8. Shiftan Yoram, Ben-Akiva, M.E., $10^{\text {th }}$ Intrnational Confrnc of Travl Bhaviour Rsarch, Lucrn (2003) 